\title{
Eficacia antimicrobiana del aceite esencial de tomillo (Thymus vulgaris) sobre una cepa de Staphylococcus aureus
}

\author{
ANTimicrobial efFicACy of Thyme esSENTIAL OIL (Thymus vulgaris) on A \\ Staphylococcus aureus STRAIN \\ Mayra Montero-Recalde ${ }^{1,2}$, Juan Carlos Mira ${ }^{1}$, Diana Avilés-Esquivel', \\ Pilar Pazmiño-Miranda ${ }^{1}$, Ramiro Erazo-Gutiérrez ${ }^{1}$
}

\section{Resumen}

El trabajo de investigación tuvo como objetivo evaluar la eficacia antimicrobiana in vitro del aceite esencial de tomillo (Thymus vulgaris) sobre Staphylococcus aureus. Se evaluaron concentraciones al 1, 5, 10, 30, 50, 70 y 90\% en dilución en etanol al $96.8 \%$. Se determinó la Concentración Mínima Inhibitoria mediante el método de microdilución en caldo. El inóculo bacteriano se estandarizó al 0.5 de la escala de MacFarland en espectofotómetro, teniendo como resultado que el tubo al $1 \%$ de aceite de tomillo no presentó turbidez. Este, al ser sembrado en agar Mueller-Hinton determinó la Concentración Bactericida Mínima donde no se observó crecimiento de colonias. Los resultados indican que los tratamientos al 5 y $10 \%$ no son significativamente diferentes $(\mathrm{p}<0.05)$ con valores de halos de inhibición de $15.35 \mathrm{~mm}$ y $15.9 \mathrm{~mm}$, respectivamente, en comparación al $1 \%$ que presentó $12.2 \mathrm{~mm}$ de halo de inhibición.

Palabras clave: concentración mínima bactericida; concentración mínima inhibitoria; MacFarland

\section{Abstract}

The objective of this study was to evaluate the in vitro antimicrobial efficacy of thyme essential oil (Thymus vulgaris) on Staphylococcus aureus. Concentrations at 1, 5, $10,30,50,70$ and $90 \%$ were evaluated in $96.8 \%$ dilution in ethanol. The Minimum Inhibitory Concentration was determined by the broth microdilution method. The bacterial inoculum was standardized to 0.5 of the MacFarland scale in spectrophotometer, with the result that the $1 \%$ tube of thyme oil did not present turbidity. This, when cultured on MuellerHinton agar, determined the Minimum Bactericidal Concentration where no colony growth

\footnotetext{
${ }^{1}$ Universidad Técnica Ambato, Campus Querochaca, Cevallos, Tungurahua, Ecuador

${ }^{2}$ E-mail:ma.montero@uta.edu.ec
}

Recibido: 19 de octubre de 2017

Aceptado para publicación: 2 de marzo de 2018 
was observed. The results indicate that treatments at 5 and $10 \%$ were not significantly different $(\mathrm{p}<0.05)$ with values of inhibition halos of $15.35 \mathrm{~mm}$ and $15.9 \mathrm{~mm}$, respetively compared to $1 \%$ concentration that presented $12.2 \mathrm{~mm}$ of halo of inhibition.

Key words: minimum bactericidal concentration; minimum inhibitory concentration; MacFarland

\section{INTRODUCCIÓN}

Staphylococcus aureus se encuentra mayormente en los conductos nasales, pero también se le encuentra en la piel, tracto gastrointestinal y en la cavidad oral (Todar, 2017). Es una bacteria gram-positiva esférica (Grijalva et al., 2014) que al ser observada en el microscopio presenta una forma de racimo (Arteaga-Delgado et al., 2016). Esta bacteria patógena es causante de una gran cantidad de infecciones cutáneas de tejidos blandos, pleuropulmonares y osteoarticulares (Tong et al., 2015).

Se ha demostrado que $S$. aureus es resistente a antibióticos como la meticilina (Aires-de-Sousa, 2017), haciéndose cada vez más necesario el uso de nuevas alternativas para su control, como podría ser el uso de extractos vegetales (Pereira Arantes et al., 2016).

El aceite de Thymus vulgaris muestra actividad antifúngica y antimicrobiana (Matiz et al., 2015) por su componente mayoritario que es el 1,8-cineol en un $21.5 \%$, seguido del B-pineno con $20 \%$ y el o-cimeno con $17.9 \%$ (Coy y Acosta, 2013), variando su composición de acuerdo al genotipo, localización geográfica, periodo de cosecha y método de extracción (Nevas et al., 2004). Diversos estudios demuestran su acción contra $S$. aureus a una concentración mínima inhibitoria del $0.03 \% \mathrm{v} / \mathrm{v}$ (Reyes et al., 2014).

El trabajo de investigación tuvo como objetivo evaluar la eficacia antimicrobiana in vitro del aceite esencial de tomillo (Thymus vulgaris) sobre Staphylococcus aureus.

\section{Materiales y Métodos}

La investigación se realizó en el Laboratorio de Bacteriología de la Facultad de Ciencias Agropecuarias de la Universidad Técnica de Ambato (Campus Querochaca), ubicada en el cantón Cevallos, Tungurahua, Ecuador, a $2883 \mathrm{msnm}$. El laboratorio estuvo bajo ambiente controlado a $29{ }^{\circ} \mathrm{C}$ y $40 \%$ de humedad.

Se adquirió $5 \mathrm{~kg}$ de tomillo en un mercado de la ciudad de Riobamba, provincia de Chimborazo. El material fue lavado con agua destilada y secado en un lugar ventilado y obscuro por 24 horas. El aceite fue obtenido mediante destilación por arrastre de vapor en equipo tipo Clevenger, para lo que se añadió 1.5 litros de agua destilada por kilo de material vegetal. Las concentraciones del aceite esencial de tomillo utilizadas fueron de 1,5, $10,30,50,70$ y $90 \%$ (v/v), utilizando como solvente el etanol al $96.8 \%$, calculadas de manera porcentual, en $5 \mathrm{ml}$ de volumen total para cada concentración.

La cepa certificada Staphylococcus aureus $A T C C{ }^{\circledR} B A A-976^{\mathrm{TM} *}$ fue adquirida del distribuidor en Ecuador MEDIBAC (Corporate Headquarters, Minnesota, EEUU). Para determinar la concentración mínima inhibitoria y concentración mínima bactericida se colocó la cepa en agar Manitol y con un asa bacteriológica se realizó el estriamiento por el método escocés e incubó a $37^{\circ} \mathrm{C}$ durante $24 \mathrm{~h}$. Se siguió la metodología descrita por García (2006) utilizando el método de microdilución en caldo o de KirbyBauer, en donde se tomaron cinco colonias aisladas de la cepa certificada y se las trans- 
firió a $5 \mathrm{ml}$ de caldo Cerebro-Corazón, estandarizado en el espectrofotómetro con el fin de obtener un valor de 0.4 de absorbancia. La solución resultante tuvo $1 \times 10^{8}$ Unidades Formadoras de Colonias (UFC). Se colocó 1 $\mathrm{ml}$ de la escala estandarizada en tubos de ensayo más $1 \mathrm{ml}$ de las concentraciones del aceite esencial de tomillo y fueron incubados a $37^{\circ} \mathrm{C}$ durante $24 \mathrm{~h}$, estableciendo la menor turbidez como la concentración mínima inhibitoria. Luego, al realizar la siembra de los tubos que presentaron menor turbidez en agar MacConkey se determinó la concentración mínima bactericida y su interpretación valorada a través del cero crecimiento de colonias en placa.

Para la prueba de difusión por disco, se tomaron cinco colonias de la cepa certificada cultivada previamente por $24 \mathrm{~h}$ en agar Manitol salado y se inocularon en $5 \mathrm{ml}$ de caldo Cerebro-Corazón. Se incubaron a $37{ }^{\circ} \mathrm{C}$ durante $2-3 \mathrm{~h}$ hasta que apareció una turbidez semejante al tubo $\mathrm{N} .^{\circ} 0.5$ de la escala de MacFarland. La solución resultante tuvo $1 \times 10^{8}$ UFC. Una vez estandarizada la cepa se cultivó por estriado múltiple en agar Mueller Hinton, dejando reposar por $10 \mathrm{~min}$ antes de colocar los discos de sensibilidad OXOID impregnados con las dosis de aceite de tomillo y etanol al $96.8 \%$ como testigo. Se colocaron cuatro discos de sensibilidad en la superficie del agar de cada placa y se incubaron a $37^{\circ} \mathrm{C}$ durante $24 \mathrm{~h}$. Posteriormente se midieron los halos de inhibición usando una regleta.

\section{Resultados}

El comportamiento de la cepa Staphylococcus aureus ATCC® BAA976 ${ }^{\mathrm{TM}} *$ frente al incremento en las concentraciones de tomillo mostró actividad específica observada en la turbidez de las muestras, demostrando que, desde la concentración de $1 \%$ en adelante no presentó turbidez y, por tanto, no existió crecimiento bacteriano.

En la concentración bactericida mínima no se apreció crecimiento de colonias en agar Mueller Hinton, por lo tanto, las concentraciones de aceite de tomillo al 1, 5, 10,30,50, 70 y $90 \%$ no permitieron el desarrollo bacteriano de la cepa de Staphylococcus auerus $A T C C{ }^{\circledR} B A A-976^{\mathrm{TM} * *}$

En el Cuadro 1 se observa que los resultados de las diluciones de los tratamientos al 5 y $10 \%$ fueron estadísticamente similares, en tanto que el halo de inhibición en la concentración de $1 \%$ fue significativamente menor $(\mathrm{p}<0.05)$. Es importante indicar que

Cuadro 1. Halos de sensibilidad ( $\mathrm{mm}$ ) del aceite esencial de tomillo (Thymus vulgaris) frente a Staphylococcus aureus

\begin{tabular}{cccccccc}
\hline & \multicolumn{3}{c}{ Concentración } & \multirow{2}{*}{ EE } & CV & \multirow{2}{*}{ Valor de P } \\
\cline { 2 - 4 } & $1 \%$ & $5 \%$ & $10 \%$ & & & \\
\hline Staphylococcus aureus & $12.2^{\mathrm{b}}$ & $15.35^{\mathrm{a}}$ & $15.9^{\mathrm{a}}$ & 0.48 & 7.38 & 0.0003 \\
\hline
\end{tabular}

a,b Medias con una letra común no son significativamente diferentes $(p<0.05)$. EE, error estándar; CV, coeficiente de variación 
no se pudo determinar la sensibilidad a las concentraciones de $30,50,70$ y $90 \%$ ya que el crecimiento bacteriano en placa quedó totalmente inhibido.

\section{Discusión}

El aceite esencial de tomillo resultó altamente eficaz sobre la cepa Staphylococcus aureus, en forma similar a otros estudios (Sartoratto et al., 2004; Imelouane et al., 2009; Coy y Acosta, 2013; Fahimi et al., 2014) donde se utilizó aceite esencial de Thymus vulgaris como antimicrobiano contra $S$. aureus. No obstante, el extracto acuoso de tomillo no fue efectivo en el estudio de Herrera y García (2006), indicando que este tipo de extracto funciona mejor en condiciones anaerobias, mientras que Hammad et al. (2007) señalan que la efectividad antimicrobiana del tomillo en estado acuoso varía en función de la concentración.

La Concentración Mínima Inhibitoria (CMI) evidenció un efecto claramente marcado a partir del $1 \%$ del aceite esencial de tomillo sobre la cepa de $S$. aureus, resultados similares a los obtenidos con el $1.23 \%$ por De Souza et al. (2008) y con $0.3 \%$ por Hammad et al. (1999) y Sadiki et al. (2014). Por otro lado, García (2006) determinó una CMI de $2.77 \%$, haciendo mención que la variación se debió al empleo de extracto alcohólico, el cual necesita de mayor concentración para inhibir el crecimiento bacteriano. La comparación de datos obtenidos en este estudio con respecto a resultados de otros estudios resulta compleja. Asi, Hammer et al. (1999) mencionan que la composición de aceites y extractos de T. vulgaris cambia según las condiciones climáticas y ambientales de cada región.

Los resultados de la prueba de sensibilidad antimicrobiana del aceite esencial de $T$. vulgaris sobre $S$. aureus se asemejan a los obtenidos por Zeghad y Merghem (2013), quienes utilizaron aceite esencial de $T$. vulgaris al $30 \%$, obteniendo halos de inhibición entre 10 y $15 \mathrm{~mm}$. De igual manera, Acosta et al. (2000), reportaron halos de 8 y $20 \mathrm{~mm}$ en concentraciones al 5 y $10 \%$, respectivamente.

\section{Conclusiones}

- El aceite esencial de tomillo (Thymus vulgaris) demostró una alta eficacia antimicrobiana in vitro sobre la cepa de Staphylococcus aureus.

- La concentración mínima bactericida de aceite esencial de tomillo que impidió el desarrollo de colonias bacterianas fue de $1 \%$.

- Concentraciones de 30\% y mayores de aceite esencial de tomillo inhibieron totalmente el crecimiento bacteriano.

\section{Literatura Citada}

1. Acosta O, Castro A, Roque M, Felix L. 2000. Composición química del aceite esencial de Thymus vulgaris $\mathrm{L}$ «Tomillo», por cromatografía de gasesespectrometro de masa GC/MS y análisis de su actividad antimicrobiana. Cienc Invest 3(2): 69-78.

2. Arteaga-Delgado LC, Espinosa-López Y, Chávez-Vivas M. 2016. Prevalencia de Staphylococcus aureus que coloniza el personal de salud de un hospital de la ciudad de Cali. Cienc Salud 14(1): 9-19. doi: 10.12804/revsalud14.01.2016.01

3. Aires-de-Sousa M. 2017. Methicillinresistant Staphylococcus aureus among animals: current overview. Clin Microbiol Infec 23: 373-380. doi: 10.1016/ j.cmi.2016.11.002

4. Corey R, Good S, Jiang H, Moeck G, Wikler M, Green S, Manos P, et al. 2014. Single-dose oritavancin compared to 7-10 days of vancomycin in the treatment of gram-positive acute 
bacterial skin and skin structure infections: the SOLO II noninferiority study. Clin Infect Dis 60: 254-262. doi: 10.1093/cid/ciu778

5. Coy A, Acosta G. 2013. Actividad antibacteriana y determinación de la composición química de los aceites esenciales de romero (Rosmarinus officinalis), tomillo (Thymus vulgaris) y cúrcuma (Curcuma longa) de Colombia. Rev Cubana Plant Med 18: 237-246.

6. De Souza Prestes L, Frascolla R, Santin R, Ziemann dos Santos M, Costa Schram R, Alves Rodrigues M, Araújo Meireles M. 2008. Actividad de extractos de orégano y tomillo frente a microorganismos asociados con otitis externa. Rev Cubana Plant Med 13(4).

7. Fahimi S, Hajimehdipoor $H$, Shabanpoor H, Bagheri F, Shekarchi M. 2014. Synergic antibacterial activity of some essential oils from lamiaceae. Res J Pharmacog 2(3): 23-29.

8. García C. 2006. Actividad antibacteriana de extractos vegetales en cepas hospitalarias de Staphylococcus aureus con resistencia múltiple. Tesis de pregrado. Torreón, México: Univ. Autónoma Agraria Antonio Narro. $100 \mathrm{p}$.

9. Hammad M, Sallal AK, Darmani H. 2007. Inhibition of Streptococcus mutans adhesion to buccal epithelial cells by an aqueous extract of Thymus vulgaris. Int J Dent Hyg 5: 232-235. doi: 10.1111/j.1601-5037.2007.00266.x

10. Hammer KA, Carson CF, Riley TV. 1999. Antimicrobial activity of essential oils and other plant extracts. J Appl Microbiol 86: 985-990. doi: 10.1046/ j.1365-2672.1999.00780.x

11. Herrera F, García R. 2006. Evaluación in vitro del efecto bactericida de extractos acuosos de laurel, clavo, canela y tomillo sobre cinco cepas bacterianas patógenas de origen alimentario. Bistua 4: 13-19.

12. Imelouane B, Khedid K, Bachiri A, Ankit M, Amhamdi H, Wathelet J. 2009. Chemical composition and antimicrobial activity of essential oil of thyme (Thymus vulgaris) from Eastern Morocco. Intet J Agric Biol 11: 205-208.

13. Matiz G, Fuentes K, León G. 2015. Microencapsulación de aceite esencial de tomillo (Thymus vulgaris) en matrices poliméricas de almidón de ñame (Dioscorea rotundata) modificado. Rev Colomb Cienc Quím Farm 44: 189-207. doi: 10.15446/rcciquifa.v44n2.56293

14. Nevas M, Korhonen A, Lindström M, Turkki P, Korkeala H. 2004. Antibacterial efficiency of Finnish spice essential oils against pathogenic and spoilage bacteria. J Food Prot 67: 199-202.

15. Pereira Arantes V, Fernandes dos Santos L, Da Silva K, Oliveira da Silva G, Meireles Costa G. 2016. Estudo comparativo da atividade antibacteriana de extractos vegetais de Senna spectabilis, Rosmarinus officinalis E Eugenia uniflora frente à cepa padrão de Pseudomonas aeruginosa ATCC 27853, Staphylococcus aureus ATCC 6538 E Streptococcus pyogenes ATCC 19. Arq Ciênc Saúde UNIPAR Umuarama 20: 151-158.

16. Reyes F, Palou E, López A. 2014. Métodos de evaluación de la actividad antimicrobiana y de determinanción de los componentes químicos de los aceites esenciales. Temas Selectos de Ingeniería de Alimentos 8(1): 68-78.

17. Sadiki M, Balouiri M, Barkai H, Maataoui H, Koraichi S, Elabed S. 2014. Synergistic antibacterial effect of Myrtus communis and Thymus vulgaris essential oils fractional inhibitory concentration index. Int J Pharm Pharm Sci 6: 121-124.

18. Sartoratto A, Machado A, Delarmelina C, Figueira M, Duarte M, Rehder V. 2004. Composition and antimicrobial activity of essential oils from aromatic plants used in Brazil. Braz J Microbiol 35: 275-280. doi: 10.1590/S151783822004000300001

19. Todar K. 2017. Staphylococcus aureus and Staphylococcal Disease. In: Todar's online textbook of bacteriology. [Internet]. Available in: www.-textbookofbacteriology.net/staph.html 
20. Tong SY, Davis JS, Eichenberger E, Holland TL, Fowler VG. 2015. Staphylococcus aureus infections: epidemiology, pathophysiology, clinical manifestations, and management. Clin
Microbiol Rev 28: 603-661. doi: 10.1128/ CMR.00134-14

21. Zeghad N, Merghem R. 2013. Antioxidant and antibacterial activities of Thymus vulgaris L. Med Aromatic Plant Res J 1: 5-11. 